\title{
Assessment of Rainstorm Disaster-causing Force of Flood Risk in Central and Eastern China
}

\author{
Dapeng Huang ${ }^{1,2}$ Lei Zhang ${ }^{3}$ \\ ${ }^{1}$ National Climate Center, China Meteorological Administration, Beijing 100081, China \\ ${ }^{2}$ Collaborative Innovation Center on Forecast and Evaluation of Meteorological Disasters, Nanjing \\ University of Information Science \& Technology, Nanjing 210044, China \\ ${ }^{3}$ National Meteorological Center, China Meteorological Administration, Beijing 10081, China
}

\section{我国中东部地区洪港灾害风险的 暴雨致灾力评估}

\author{
黄大鹏 ${ }^{1,2}$ 张蕾 $^{3}$ \\ ${ }^{1}$ 中国气象局国家气候中心, 北京 100081 , 中国 \\ ${ }^{2}$ 南京信息工程大学气象灾害预报预警与评估协同创新中心, 南京 210044 , 中国 \\ 3 国家气象中心, 北京 100081 , 中国
}

\begin{abstract}
Using the 1961-2008 daily precipitation data from 300 meteorological stations in central and eastern China, seven rainstorm factors were selected to construct a synthesis indicator of rainstorm disaster-causing force by principal component analysis according to the principle that rainstorm disaster-causing factor should include the influence of rainstorm on flood disaster in three aspects of intensity, accumulation and continuity. Based on the rainstorm disaster-causing factor, the influence

资助项目: 国家自然科学基金项目 “多时空尺 度洪涝灾害风险评估研究 (41101517)”, 国家 公益性行业专项 “台风/暴雨灾害损失及服务 效益评估关键技术与系统研发 (GYHY201506051)”

作者简介: 黄大鹏 (1978-), 男, 安徽潜山人, 博士, 副研究员, 主要从事气象灾害风险评估、 气候变化影响评估、遥感与 GIS 应用研究等。 E-mail: huangdp@cma.gov.cn
\end{abstract}

of rainstorm on flood risk was assessed in central and eastern China. The results show that the rainstorm disaster-causing force decreases approximately form southeast to northwest, it is highest in most parts of Hainan, central and coastal area of Guangdong, coastal area of Guangxi. The rainstorm disaster-causing force is relatively high in other regions of Guangdong and Guangxi, most parts of Fujian, south and east of Jiangxi, south of Anhui, east of Hubei, southwest of Zhejiang, The areas with medium value are Hunan, west and south of Jiangxi, south and north-central part of Hubei, most of Anhui, most of Zhejiang, Jiangsu, southeastern Henan, eastern coastal area of Liaoning. The other regions in central and eastern China have relatively low and even lower value of rainstorm disaster-causing force.

Keywords: rainstorm factors, rainstorm disaster-causing force, flood risk, Central and Eastern China 
Risk Analysis and Crisis Response in Big Data Era (RAC-16)

\section{摘要}

利用我国中东部地区 300 个气象站点 1961-2008 年的逐日降水量资料, 根据洪涝灾 害的暴雨影响必须反映暴雨强度、暴雨累积作 用、暴雨连续性的原则, 选取多年平均日最大 降雨量、多年平均最大 3 天降雨量、多年平均 暴雨日数、多年平均暴雨累积量、多年平均暴 雨最大过程累积量、多年平均暴雨过程累积量、 暴雨持续性等 7 个暴雨因子进行分析, 并采用 主成分分析方法构建洪涝灾害风险的暴雨致 灾力指标, 对我国中东部地区洪涝灾害的暴雨 致灾力进行评估, 评估结果表明: (1) 暴雨致 灾力整体上大致呈现由东南向西北逐渐减少 的规律; (2) 暴雨致灾力高值区位于海南大部、 广东中部和沿海、广西沿海地区; 较高值主要 位于广东和广西两省除沿海以外地区、福建大 部、江西北部和东部、安徽南部、湖北东部、 浙江西南部等; 中值区主要位于湖南、江西西 部和南部、湖北南部及中北部、安徽大部、浙 江大部、江苏、河南东南部、辽宁东部沿海; 其余地区暴雨致灾力为较低值或低值。

关键字: 暴雨影响因子, 暴雨致灾力, 洪涝 灾害风险, 中国中东部地区

\section{1. 引言}

洪涝灾害不论在世界范围还是在中国 都是各种自然灾害之中造成损失最大的一 种灾害。目前, 全球各种灾害造成的损失, 洪涝占 $40 \%$, 热带气旋占 $20 \%$, 干早占 $15 \%$, 地震占 $15 \%$, 其余占 $15 \%^{[1]}$ 。中国地域辽阔, 自然地理、气候条件复杂, 决定了中国是一 个自然灾害频繁发生的国家, 在世界上上属 洪涝灾害最严重的国家之一 ${ }^{[2]}$ 。国内外学者 对洪涝灾害开展了大量研究工作, 洪涝灾害 风险研究已成为灾害学研究的热点 ${ }^{[3]}$ 。目前 国内外学者评估洪涝灾害风险多从危险性、 暴露性和脆弱性的概念模型 ${ }^{[4-5]}$ 出发, 相应 的洪涝灾害风险评估过程包括洪涝灾害致 灾因子危险性评估、承灾体暴露性和脆弱性 评估。也有学者提出了洪涝灾害风险评估的 四因子概念模型, 在传统的洪涝灾害风险概 念模型基础之上, 增加了抗灾减灾能力的评 估 ${ }^{[6]}$ 。尽管众多研究在洪涝灾害风险评估中 对暴雨危险性进行了分析与评估, 但选用的
暴雨指标较为单一或简单 ${ }^{[7-13]}$, 难以综合反 映暴雨对洪涝灾害的影响, 因此有必要对暴 雨致灾力进行深入研究。本文以我国中东部 地区为研究区, 开展洪涝灾害的暴雨影响因 子分析, 构建洪涝灾害的暴雨致灾力指标, 对我国中东部地区洪涝灾害风险的暴雨致 灾力进行评估, 为实现最终的洪涝灾害风险 评估提供科学可靠的致灾因子分析。

本文研究的我国中东部地区包括: 黑龙 江、吉林、辽宁、河北、北京、天津、河南、 山东、山西、江苏、上海、安徽、浙江、湖 北、湖南、江西、福建、广东、广西和海南 共 20 个省级行政单元。该区域人口密集, 2014 年末人口 104161 万人, 占全国人口 $76.2 \%$ 。中东部地区是我国重要的工农业生 产基地, 经济发展基础好。土地面积约 299.1 万 $\mathrm{km}^{2}$, 占国土面积的 $31.2 \%$ 。2014 年 GDP 为 636138.7 亿元, 占全国 GDP 总量的 $88.3 \%$ 。 中东部地区降水丰沛, 暴雨强烈, 洪涝灾害 频繁发生且危害严重, 是我国洪涝灾害的主 要发生地。人口、经济、暴雨、洪涝的集中, 使得中东部地区成为我国洪涝灾害研究的 重点区域。

\section{2. 数据来源与方法}

\section{1 数据来源}

数据由国家气象信息中心提供, 包括我 国中东部地区 300 个气象站点 (国家基本气 象站点和国家基准气候站点）1961-2008 年 的逐日降水量资料。

\section{2 研究方法}

（1）暴雨影响因子选取

暴雨对洪涝灾害的影响主要表现在暴雨 强度、暴雨累积作用和暴雨持续性等方面, 因 此, 确立了暴雨影响因子的选取原则: (1) 必 须包括反映暴雨强度作用的因子; (2) 必须包 括反映暴雨累积作用的因子; (3) 必须包括反 映暴雨持续性的因子。

根据以上原则, 选取了 7 个暴雨影响因子, 具体因子名称及含义如表 1 所示。利用 Matlab 软件建立暴雨影响因子计算程序, 从原始逐日 降水量资料中提取以下 7 个暴雨影响因子。

(2) 主成分分析

以上初步选取的 7 个暴雨影响因子之间 
Risk Analysis and Crisis Response in Big Data Era (RAC-16)

表1 我国中东部地区洪港灾害暴雨影响因子选取

\begin{tabular}{|c|c|c|}
\hline 因子 & 名称 & 含义 \\
\hline$X_{1}$ & 多年平均最大 1 天降雨量 & 年最大 1 天降水量的多年 (1961-2008 年) 平均值 \\
\hline$X_{2}$ & 多年平均最大 3 天降雨量 & 年最大 3 天降水量的多年 (1961-2008 年) 平均值 \\
\hline$X_{3}$ & 多年平均暴雨以上降水日数 & 年暴雨日数 ( $\geqslant 50 \mathrm{~mm})$ 的多年 (1961-2008 年) 平均值 \\
\hline$X_{4}$ & 多年平均暴雨以上降水累积量 & $\begin{array}{l}\text { 年暴雨 }(\geqslant 50 \mathrm{~mm}) \text { 降水量的多年 (1961-2008 年) 平均值 } \\
\text { 年最大暴雨过程降水的多年 (1961-2008 年) 平均值。暴雨 }\end{array}$ \\
\hline$X_{5}$ & 多年平均暴雨最大过程累积量 & $\begin{array}{l}\text { 过程指一次连续多日降水, 其中至少包含一个暴雨日 }(\geqslant \\
50 \mathrm{~mm}) \text {, 出现日降水量 }<0.1 \mathrm{~mm} \text { 则暴雨过程结束。 }\end{array}$ \\
\hline$X_{6}$ & 多年平均暴雨过程累积量 & $\begin{array}{l}\text { 年所有暴雨过程总降水量的多年 (1961-2008 年) 平均值。 } \\
\text { 暴雨过程定义同上。 }\end{array}$ \\
\hline$X_{7}$ & 暴雨持续性 & $\begin{array}{l}\text { 暴雨日 }(\geqslant 50 \mathrm{~mm}) \text { 出现日期的前后 } 3 \text { 天里出现大雨以上降 } \\
\text { 水 }(\geqslant 25 \mathrm{~mm}) \text { 的频率。 }\end{array}$ \\
\hline
\end{tabular}

相关性显著, 因此利用主成分分析法 ${ }^{[14,15]}$ 对我 国中东部 300 个站点的 7 个暴雨影响因子进行 最佳综合与简化，以一个物理意义清晰且方 差占总方差大部分的综合变量取代原来的多 个影响因子, 以此作为洪涝灾害风险的暴雨致 灾力指标, 可避免各影响因子之间的信息重叠 问题, 从而简化所研究的问题。

(3) 空间插值与数据分级

利用 ArcGIS 软件空间分析模块中的反距 离加权插值方法, 将我国中东部地区 300 个站 点的暴雨影响因子和暴雨致灾力指标插值成 $10 \mathrm{~km} \times 10 \mathrm{~km}$ 的格网, 并采用自然断裂点 (Natural Breaks) 的方法对数据进行分级, 制作我国中东部地区暴雨影响因子空间分布 图和暴雨致灾力空间分布图, 以反映各暴雨影 响因子和暴雨致灾力的空间分布规律。

\section{3. 我国中东部地区洪港灾害的暴雨影响因子 分析}

通过对提取的 7 个暴雨影响因子的空间 插值分析, 得到我国中东部地区洪涝灾害风险 的 7 个暴雨影响因子空间分布图 (图 1.a、图 1.b、图 1.c、图 1.d、图 1.e、图 1.f、图 1.g)。 7 个暴雨影响因子的空间分布大致都呈现出由 东南向西北方向从高值向低值渐变的规律, 各 影响因子的具体分布形势如下。

\section{1 多年平均最大 1 天降雨量}

多年平均最大 1 天降雨量的高值区位于 海南、广东和广西两省沿海地区等, 达到 $130.6 \mathrm{~mm}$ 以上。其次为广东和广西的大部地
区、福建东南沿海以及鄂皖赣三省交界区域 等, 达到 $107.6 \mathrm{~mm}$ 以上。黑龙江、吉林、 山西和河北西北部地区等为低值区, 多年平 均最大 1 天降雨量在 $66.8 \mathrm{~mm}$ 以下。浙江中 北部地区、湖北西北部、河南西部及北部、 山东北部、河北东部及南部地区、北京市大 部地区及辽宁除东部沿海以外的大部地区 等为较低值区, 多年平均最大 1 天降雨量在 $90.2 \mathrm{~mm}$ 以下。其它地区为中值区, 多年平 均最大 1 天降雨量在 $90.2 \mathrm{~mm}-107.6 \mathrm{~mm}$ 之间。

\section{2 多年平均最大 3 天降雨量}

多年平均最大 3 天降雨量的高值区位于 海南、广东和广西两省沿海地区等, 达到 $196.9 \mathrm{~mm}$ 以上。其次为广东和广西的大部地 区、湖北东部、安徽南部、江西北部及中东 部以及福建大部地区等, 达到 $153.0 \mathrm{~mm}$ 以 上。黑龙江、吉林、山西和河北西北部地区 等为低值区, 多年平均最大 3 天降雨量在 $90.4 \mathrm{~mm}$ 以下。湖北西北部、河南西部及北 部、山东北部、河北东部及南部地区、北京 市大部地区及辽宁除东部沿海以外的大部 地区等为较低值区, 多年平均最大 3 天降雨 量在 $123.3 \mathrm{~mm}$ 以下。其它地区为中值区, 多年平均最大 3 天降雨量在 $123.3 \mathrm{~mm}-153.0 \mathrm{~mm}$ 之间。

\section{3 多年平均暴雨以上降水日数}

多年平均暴雨以上降水日数的高值区 位于海南大部、广东和广西两省沿海地区等, 达到 7.1 日以上。其次为广东和广西的大部 地区、安徽南部、江西北部地区等, 达到 5.0 
Risk Analysis and Crisis Response in Big Data Era (RAC-16)
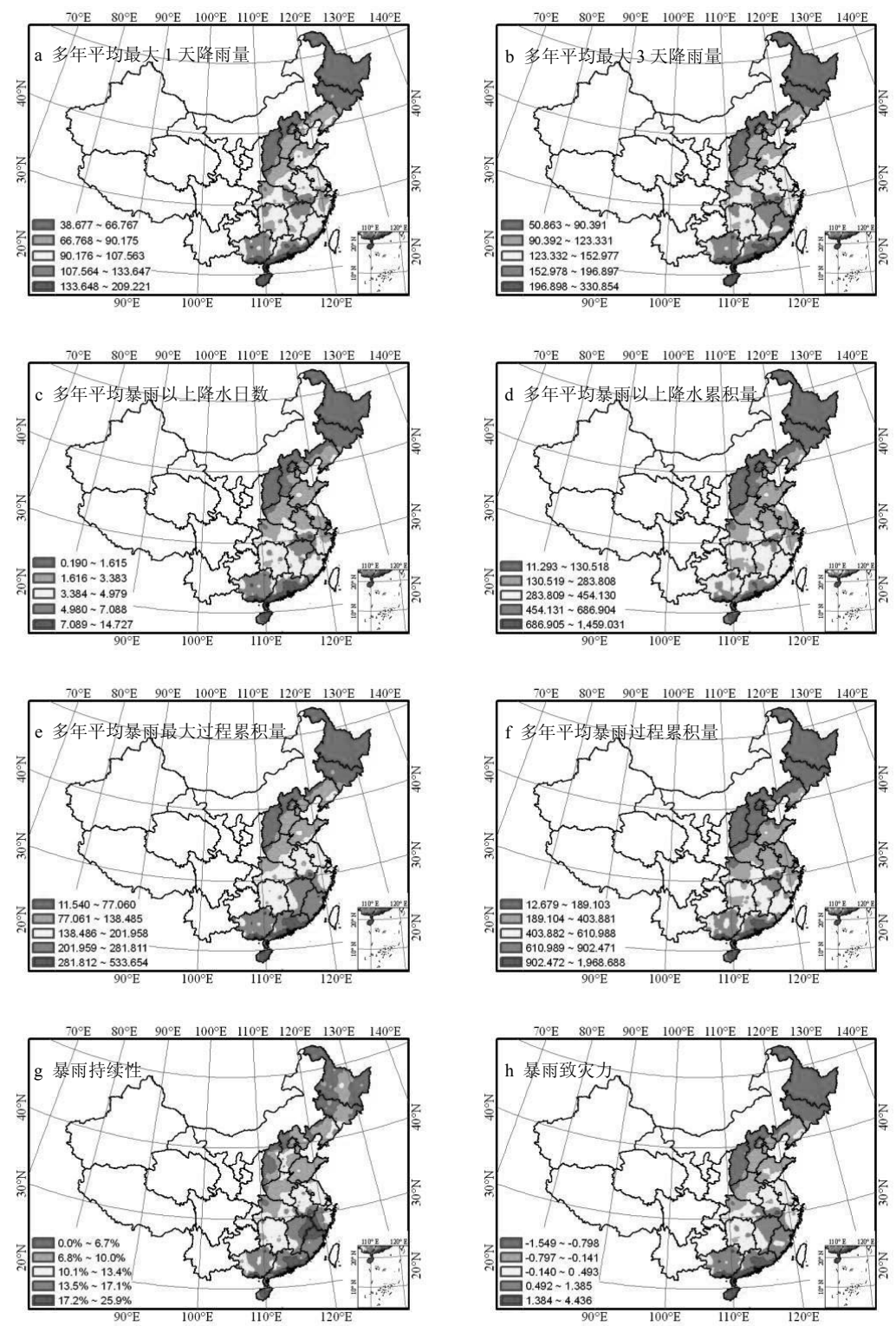

图1 我国中东部地区洪涝灾害风险的暴雨影响因子及暴雨致灾力空间分布

日以上。黑龙江、吉林、山西、辽宁西北部、 北京西部及北部、河北西部和南部地区等为 低值区, 多年平均暴雨以上降水日数为 1.6 日以下。辽宁中部、北京东南部、天津、河 北东部、山东、河南大部、湖北西北部、安 徽北部、江苏南部和浙江北部地区等为较低
值区，多年平均暴雨以上降水日数为 3.4 日 以下。其它地区为中值区, 多年平均暴雨以 上降水日数在 3.4 日-5.0 日之间。

\section{4 多年平均暴雨以上降水累积量}

多年平均暴雨以上降水累积量的高值 区位于海南大部、广东和广西两省沿海地区 


\section{Risk Analysis and Crisis Response in Big Data Era (RAC-16)}

等, 达到 $686.9 \mathrm{~mm}$ 以上。其次为广东中东 部、广西南部部分地区、安徽和江西两省交 界部分地区等，达到 $454.1 \mathrm{~mm}$ 以上。黑龙 汇、吉林、山西、辽宁西北部、北京、河北 西部和南部地区等为低值区, 多年平均暴雨 以上降水累积量在 $130.5 \mathrm{~mm}$ 以下。辽宁中 部和南部、天津、河北东部、山东、河南大 部、湖北中部和西部、安徽北部、湖南南部、 江苏大部和浙江中北部地区等为较低值区, 多年平均暴雨以上降水累积量为 $283.8 \mathrm{~mm}$ 以下。其它地区为中值区，多年平均暴雨以 上降水累积量在 $283.8 \mathrm{~mm}-454.1 \mathrm{~mm}$ 之间。

\section{5 多年平均暴雨最大过程累积量}

多年平均暴雨最大过程累积量的高值 区位于海南大部、广西沿海、广东沿海和中 部等, 达到 $281.8 \mathrm{~mm}$ 以上。其次为广西大 部、广东大部、江西东部和北部、福建、浙 江西南部、安徽南部等, 达到 $202.0 \mathrm{~mm}$ 以 上。黑龙江、吉林、山西、北京西北部、河 北西北部地区等为低值区, 多年平均暴雨最 大过程累积量在 $77.1 \mathrm{~mm}$ 以下。辽宁大部、 北京大部、天津、河北东部和南部、山东、 河南大部、湖北西北部等为较低值区, 多年 平均暴雨最大过程累积量为 $138.5 \mathrm{~mm}$ 以下。 其它地区为中值区, 多年平均暴雨最大过程 累积量在 $138.5 \mathrm{~mm}-202.0 \mathrm{~mm}$ 之间。

\section{6 多年平均暴雨过程累积量}

多年平均暴雨过程累积量的高值区位 于海南大部、广西沿海、广东沿海和中部等, 达到 $902.5 \mathrm{~mm}$ 以上。其次为广西大部、广 东北部和西部、江西和安徽交界的部分地区 等, 达到 $611.0 \mathrm{~mm}$ 以上。黑龙江、吉林、 辽宁西北部、山西、河北大部、北京、天津 西部、河南西北部、湖南西北部等为低值区, 多年平均暴雨过程累积量在 $189.1 \mathrm{~mm}$ 以下。 辽宁东部、天津东部和北部、河南大部、湖 北西部大部地区等为较低值区, 多年平均暴 雨过程累积量为 $403.9 \mathrm{~mm}$ 以下。其它地区 为中值区, 多年平均暴雨过程累积量在 $403.9 \mathrm{~mm}-611.0 \mathrm{~mm}$ 之间。

\section{7 暴雨持续性}

暴雨持续性的高值区位于海南大部、广 西沿海、广东沿海和中部、晥浙赣闽四省交 界地区等, 达到 $17.2 \%$ 以上。其次为广西大
部、广东北部和西部、江西大部、福建大部 等, 达到 $13.5 \%$ 以上。黑龙江的东部和西部、 吉林西部、河北西北部、山西中西部和北部 为低值区, 暴雨持续性在 $6.7 \%$ 以下。黑龙 江中部、吉林中部和东部、辽宁中西部、北 京、天津、河北东部和北部、山东省、河南 大部、湖北西部为较低值区, 暴雨持续性在 $10 \%$ 以下。其它地区为中值区, 暴雨持续性 在 $10.1 \%-13.4 \%$ 之间。

\section{4. 我国中东部地区洪涝灾害风险的暴雨致灾} 力评估

\section{1 暴雨致灾力指标构建}

经主成分分析得到的第 1 主分量占总方 差的贡献率为 $94.773 \%$ 。因此, 以第 1 主成 分反映原来 7 个暴雨影响因子的综合作用, 构建洪涝灾害的暴雨致灾力指标 $(R I)$, 具 体表达式如（1）所示。

$R I=0.145 X_{1}+0.149 X_{2}+0.149 X_{3}+0.149 X_{4}$ $+0.149 X_{5}+0.149 X_{6}+0.136 X_{7}$

从物理意义上来看, 暴雨各影响因子对 综合指标的贡献均为正贡献。暴雨强度越大、 暴雨累积量越大、暴雨过程强度越大、暴雨 过程累积量越大、暴雨持续性越强, 对暴雨 致灾力指标的贡献均越大。

\section{2 暴雨致灾力评估}

从图 1.h 暴雨致灾力空间分布图上可以 看出, 暴雨致灾力整体上大致呈现由东南向 西北逐渐减少的规律。暴雨致灾力高值区位 于海南大部、广东中部和沿海、广西沿海地 区; 较高值主要位于广东和广西两省除沿海 以外地区、福建大部、江西北部和东部、安 徽南部、湖北东部、浙江西南部等; 中值区 主要位于湖南、江西西部和南部、湖北南部 及中北部、安徽大部、浙江大部、江苏、河 南东南部、辽宁东部沿海; 较低值区位于湖 北西北部、河南大部、山东大部、天津、北 京东部和南部、河北东部和南部、辽宁大部 等。通过暴雨因子空间分布图与暴雨致灾力 空间分布图的对比可以发现, 暴雨致灾力的 空间分布规律与多年平均最大 3 天降水量及 多年平均暴雨最大过程累积量两个暴雨影 响因子的空间分布规律最为一致, 这两个指 标在某种程度上说既反映了暴雨强度也反 
映了暴雨累积作用。

\section{5. 结论与讨论}

（1）各暴雨影响因子和暴雨致灾力整体上 都大致呈现由东南向西北逐渐减少的规律, 减少的方向与我国东部季风区夏季盛行风 向具有一致性, 从某种程度上说明暴雨的产 生与夏季盛行风是息息相关的。

（2）暴雨致灾力高值区位于海南大部、广 东中部和沿海、广西沿海地区; 较高值主要 位于广东和广西两省除沿海区域以外的地 区、福建大部、江西北部和东部、安徽南部、 湖北东部、浙江西南部等; 中值区主要位于 湖南、江西西部和南部、湖北南部及中北部、 安徽大部、浙江大部、江苏、河南东南部、 辽宁东部沿海; 其余地区暴雨致灾力为较低 值或低值。

（3）暴雨致灾力的空间分布规律与多年平 均最大 3 天降水量及多年平均暴雨最大过程 累积量两个暴雨影响因子的空间分布规律 最为一致。

\section{参考文献}

[1] 廖鸿, 静波, 徐娜. 中国的洪涝灾害. 中 国减灾, 2004(6):26-28.

[2] 吴炳方, 陈述彭. 中国自然灾害灾情分 析与减灾对策. 北京: 时代科学技术出 版社, 1992.

[3] 黄大鹏, 刘闯, 彭顺风. 洪灾风险评价 与区划研究进展. 地理科学进展, 2007,26(4):11-22.

[4] Crichton D, Mounsey C. How the Insurance Industry will use its flood research. In: Proceedings of the Third MAFF Conference of Coastal and River Engineers, 1997, 131-134.

[5] Cardona, O. D.: Indicators for Disaster Risk and Risk Management. Program for
Latin America and the Caribbean: Summary Report, Manizales, Columbia: Instituto de Estudios Ambientales, Universidad Nacional de Columbia, 2005.

[6] 张会, 张继权, 韩俊山. 基于 GIS 技术 的洪涝灾害风险评估与区划研究—— 以辽河中下游地区为例. 自然灾害学 报, 2005,14(6):141-146.

[7] 周成虎, 万庆, 黄诗峰, 等. 基于 GIS 的洪水灾害风险区划研究. 地理学报, 2000,55(1):15-24.

[8] 张行南, 罗健, 陈雷, 等. 中国洪水灾 害危险程度区划。水利学报, 2000(3):1-7.

[9] 万君, 周月华, 王迎迎, 等. 基于 GIS 的湖北省区域洪涝灾害风险评估方法 研究. 暴雨灾害, 2007,26(4):328-333.

[10] 蒋新宇, 范久波, 张继权, 等. 基于 GIS 的松花江干流暴雨洪涝灾害风险评估. 灾害学,2009,24(3):51-56.

[11] 张婧, 郝立生, 许晓光. 基于 GIS 技术 的河北省洪港灾害风险区划与分析. 灾害学,2009,24(2):51-56.

[12] 张京红, 田光辉, 蔡大唫, 等. 基于 GIS 技术的海南岛暴雨洪涝灾害风险区划。 热带作物学报, 2010,31(6):1014-1019.

[13] Cheng Xianfu, Sun Honghu, Yuan Zhang et al. Flood Disaster Risk Assessment and Spatial Distribution Characteristics along the Yangtze River in Anhui Province. Journal of Risk Analysis and Crisis Responese,2014,4(4):238-242.

[14] 黄嘉佑. 气象统计分析与预报方法[M]. 北京:气象出版社,2000.

[15] 白雪梅, 赵松山. 对主成分分析综合评 价方法若干问题的探讨. 统计研 究,1995(6):49-50. 